\title{
PERANCANGAN SISTEM KERJA SIMULATOR AC (AIR CONDITIONER) MOBIL
}

\author{
Rusuminto Syahyuniar $^{1}$, Yuliana Ningsih ${ }^{2}$, Ridho Dwi Kurniawan ${ }^{3}$ \\ 1,2) Staf Pengajar Jurusan Mesin Otomotif Politeknik Negeri Tanah Laut \\ 3) Mahasiswa Mesin Otomotif Politeknik Negeri Tanah Laut \\ Naskah diterima: 20 Mei 2018 ; Naskah disetujui: 25 Juni 2018
}

\begin{abstract}
ABSTRAK
Sistem AC memiliki beberapa komponen yaitu kompresor, kondensor, receiver dryer, katup ekspansi dan evaporator, yang mana memiliki fungsinya tersendiri. Untuk itu perlu adanya suatu simulator untuk mensimulasikan sistem kerja dari simulator AC mobil. Pengujian untuk simulator ini adalah bagaimana pengaruh massa refrigerant terhadap rpm motor listrik, tekanan kerja refrigerant, suhu kondensor dan suhu evaporator.Simulator AC mobil ini digunakan sebagai media pembelajaran bagi mahasiswa mesin otomotif dibidang sistem refrigerasi mobil. Metode pengujianya adalah dengan memasukkan beberapa variasi massa refrigerant (100 gram, 200 gram, 300 gram) kedalam sistem simulator AC mobil kemudian mencatat hasil pengujian. Berdasarkan hasil pengujian massa refrigerant sangat berpengaruh terhadap sistem kerja simulator AC mobil(rpm motor listrik, tekanan kerja refrigerant, suhu kondensor dan suhu evaporator), Rpm motor listrik paling tinggi adalah pada massa refrigerant 100 gram yaitu $1446 \mathrm{rpm}$. Tekanan kerja refrigerant paling tinggi adalah pada massa refrigerant 300 gram yaitu 20 Psi / 195 Psi. Suhu kondensor paling tingi adalah pada massa refrigerant 300 gram yaitu mencapai $58,8^{\circ} \mathrm{C}$. Dan suhu evaporator paling dingin adalah pada massa refrigerant 300 gram yaitu mencapai $11,4^{\circ}$ C. Kecepatan blower evaporator juga berpengaruh terhadap sistem kerja dari simulatir AC mobil, namun tidak terlalu signifikan. Di setiap massa refrigerant rpm motor listrik paling tinggi adalah saat massa refrigerant 100 gram dan dengan kecepatan blower 1 yaitu 1446 rpm. Suhu kondensor paling tinggi adalah pada massa refrigerant 300 gram dan dengan kecepatan blower 3 yaitu mencapai $61,6^{\circ}$ C. Dan suhu evaporator paling dingin adalah pada massa refrigerant 300 dan dengan kecepatan blower 3 gram yaitu mencapai $9,2^{\circ} \mathrm{C}$.
\end{abstract}

Kata Kunci : Simulator, Air Conditioner, Mobil, Refrigrant

\section{PENDAHULUAN}

Dunia otomotif terus berkembang setiap tahun, dan juga terjadi kenaikan pada jumlah mobil pribadi maupun angkutan umum, jumlah mobil penumpang ditahun 2016 tercatat sebanyak 14.580 .666 dan mobil barang sebanyak 7.063.433 [1]. Dengan tingginya minat konsumen teknologi yang ada pun terus berkembang, salah satunya adalah sistem pendingin kabin atau sistem AC (Air Conditioner).

Sistem AC (Air Conditioning) merupakan suatu proses pengkondisian udara dimana udara itu

didinginkan, dikeringkan, dibersihkan dan disirkulasikan yang selanjutnya jumlah dan kualitas dari udara yang dikondisikan tersebut dikontrol [2]. Penggunaan sistem AC dimobil juga bertujuan agar terciptanya suhu yang nyaman bagi pengendara dan penumpang, untuk mengontrol kelembaman udara, untuk mengontrol sirkulasi udara, dan mensirkulasikan udara. Untuk dapat bekerja secara optimal sistem AC mobil memiliki beberapa komponen.

Pada sistem AC mobil ada beberapa komponen utama yang sangat penting untuk diketahui, yaitu kompresor, kondensor, katup ekspansi dan evaporator. Komponen-komponen tersebut memiliki fungsinya masing-masing, sehingga proses pengkondisian udara didalam kabin berlangsung dengan baik.Proses pengkondisian udara di dalam sistem AC mobil juga sangat dipengaruhi oleh jenis kompresor, putaran Blower, jumlah refrigerant yang ada didalam sistem dan lain lain. 
Agar cara kerja, fungsi-fungsi dan tata letak komponen dapat mudah dipahami bagi mahasiswa maka perlu adanya suatu alat pembelajaran atau simulator dari sistem AC mobil. Di workshop Politeknik Negeri Tanah Laut sendiri masih belum memiliki suatu alat pembelajaran ataupun simulator sebagai media pembelajaran dan bahan praktek bagi mahasiswa agar dapat mengembangkan pengetahuan dan kemampuan mahasiswa dibidang sistem AC mobil. Berdasarkan latar belakang tersebut penulis tertarik untuk membuat perancangan sistem kerja simulator Air Conditioner (AC) mobil.

\section{METODOLOGI}

\section{Peralatan yang digunakan}

1. Satu (1) set Toolbox

2. Vacum pump

3. Pressure gauge

4. Quick coupler

5. Tap valve refrigerant

6. Timbangan

7. Tachometer

8. Termometer

9. Stopwatch

10. Meter ukur

11. Cutter

\section{Bahan yang digunakan}

1. Refrigerant R-134a

2. Oli pelumas kompresor

3. Polycarbonate

4. Lem silikon Acetic

5. Motor listrik $1 \mathrm{Hp}$ dengan $1500 \mathrm{rpm}$

6. Pulley

7. V-belt

8. Kompresor AC mobil model 10PA15C

9. Kondensor

10. Extrafan

11. Receiver drier

12. Katup ekspansi

13. Evaporator

14. Blower evaporator

15. Hose refrigerant

\section{Diagram alir}

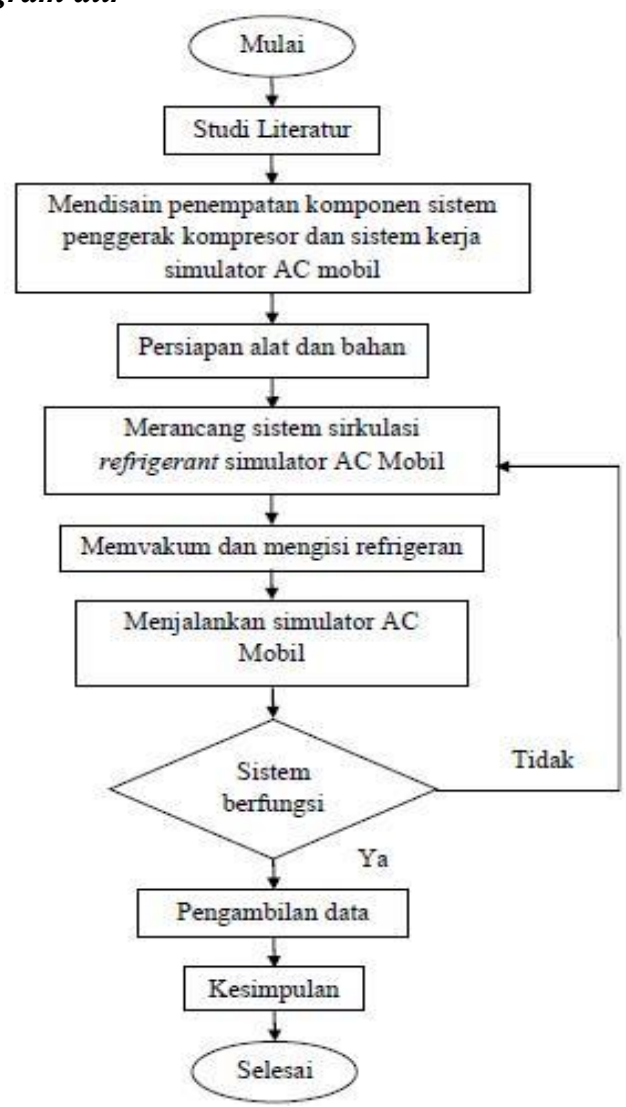

Gambar 1 Diagram alir

\section{Prosedur Pengujian Sistem Kerja Simulator AC mobil}

Untuk menguji pengaruh variasi massa refrigerant terhadap tekanan refrigerant pada kompresor disisi tekanan rendah dan tekanan tinggi dan suhu kabin disimulator AC mobil:

1. Menyiapkan alat dan bahan

2. Pasang presure gauge, hose warna biru (sisi tekanan rendah) disambungkan dengan nipple tekanan rendah dan hose warna merah (sisi tekanan tinggi) dengan nipple tekanan tinggi pada kompresor, untuk hose berwarna kuning pasang dengan nipple di vacum pump

3. Sambungkan vacum pump dengan power supply, buka valve presure gauge sisi tekanan tinggi dan tekanan rendah kemudian nyalakan vacum pump agar didalam sistem pendingin simulator AC mobil bebas dari udara, tunggu proses vacum sekitar 15 sampai 20 menit atau sampai pressure gauge sisi tekanan rendah menunjukan angka dibawah 0 (nol).

4. Tutup valve pressure gauge sisi tekanan rendah dan tinggi.

5. Timbang dan catat berat awal tabung refrigerant

6. Lepas hose pressure gauge bewarna kuning dari vacum pump kemudian pasangkan ke tabung refrigerant $\mathrm{HFC} \mathrm{R}-134 \mathrm{a}$

7. Nyalakan sistem simulator AC mobil. 
8. Buka valve pressure gauge sisi tekanan rendah agar refrigerant masuk ke dalam sistem.

9. Tutup valve presure gauge jika massa refrigerant yang masuk sudah mencapai 100 gram

10. Tutup kembali valve pressure gauge

11. Biarkan sistem pendingin simulator AC mobil sekitar 15 sampai 30 menit.

12. Kemudian ambil data tekanan refrigerant pada kompresor disisi tekanan tinggi dan tekanan rendah dan suhu kabin di simulator AC mobil

13. Mencatat hasil pengujian

14. Ulangi langkah 6 sampai 13 untuk variasi massa refrigerant 100 gram, 200 gram, dan 300 gram

15. Rapikan dan bersihkan kembali peralatan.

\section{HASIL DAN PEMBAHASAN}

\section{Penentuan Komponen Simulator AC Mobil Motor Listrik}

Pada simulator AC mobil motor listrik digunakan untuk memutar kompresor, karena pada keadaan aslinya di mobil kompresor digerakkan oleh putaran engine. Kompresor diharapkan dapat berputar pada kisaran $1000 \mathrm{rpm}$. Di workshop sudah ada tersedia motor listrik dengan daya $1 \mathrm{HP}$ dan dengan putaran $1500 \mathrm{rpm}$, sehingga motor listrik ini cocok digunakan pada simulator AC mobil

\section{Pulley}

Motor listrik yang digunakan adalah motor listrik dengan daya $1 \mathrm{HP}$ dan dengan putaran 1500 rpm, dan diharapkan putaran rpm kompresor AC mobil ada di kisaran angka $100 \mathrm{rpm}$, ukuran dimaeter puli dari kompresor adalah $145 \mathrm{~mm}$. Sehingga ratio ukuran puli yang digunakan dapat diketahui dengan persamaan berikut:

$\underline{\mathrm{n}}_{\mathrm{n} 2}={ }^{\mathrm{D} 2} \mathrm{D} 1$

Keterangan :

$\mathrm{n} 1:$ Rpm motor penggerak

n2 : Rpm mesin yang digerakkan

$\mathrm{D}_{1}$ : Diameter pulley motor

$\mathrm{D}_{2}$ : Diameter pulley mesin yang digerakan

Perhitungan :

Diketahui :

n1 : $1500 \mathrm{rpm}$

$\mathrm{n} 2: 1000 \mathrm{rpm}$

D2 : $145 \mathrm{~mm}$

$\frac{1500}{1000}={ }^{145} \mathrm{D} 1$
$\frac{1000 \times 145}{1500}$

\section{V-belt}

Berdasarkan tabel diatas tipe $V$-belt yang cocok adalah tipe $\mathrm{A}$, karena tipe $\mathrm{A}$ digunakan untuk motor listrik dengan daya $1-11 / 2 \mathrm{Hp}$, dan cocok dengan motor listrik yang akan digunakan.
Untuk $V$-belt tipe A setelah dicari dipasaran hanya ada $V$-belt tipe A-53

$V$-belt A-53 memiliki spesifikasi sebagai berikut:

Panjang : 53 inci

Berat : 0,34 lb

Temperature resistance : $-35^{\circ} \mathrm{C}$ sampai $+70^{\circ} \mathrm{C}$

Sehingga untuk menghitung jarak antar pusat pulley yang digunakan dapat dihitung dengan persamaan berikut :

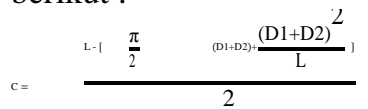

Keterangan :

C : Jarak antar pusat pulley

L : Panjang sabuk $V$-belt

$\mathrm{D}_{1}$ : Diameter pulley penggerak

$\mathrm{D}_{2}$ : Diameter pulley mesin yang

digerakkan Perhitungan :

Diketahui :

L : 53 inci : $1397 \mathrm{~mm}$

D1 : $96,67 \mathrm{~mm}$

D2 : $145 \mathrm{~mm}$

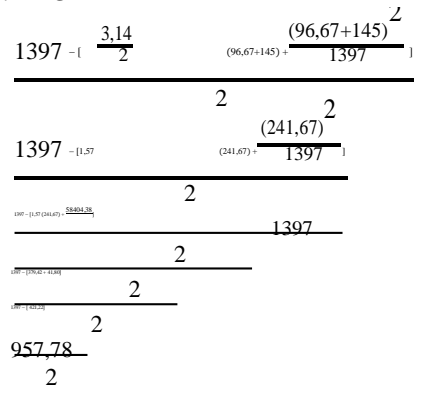

\section{Proses Pengisian Refrigerant dan Cara Kerja Simulator AC Mobil}

\section{Proses Pengisian Refrigerant}

Proses pengisian refrigerant adalah proses memasukkan zat refrigerant (R-134-a) kedalam sistem simulator AC mobil yang dilakukan setelah sistem dalam keadaan vacum (hampa udara). Setelah sistem divacum kemudian selanjutnya adalah pengisian refrigerant sesuai berat massa refrigerant yang akan diteliti, langkah langkahnya yaitu :

1. Persiapkan alat dan bahan yang diperlukan

2. pasang tap valve refrigerant (regulator kaleng refrigerant) pada refrigerant kaleng dengan cara memutar handelnya berlawanan arah jarum jam, kemudian pasangkan ke refrigerant dan putar kekanan kemudian putar handelnya berlawanan arah jarum jam.

3. Pasangkan hose warna kuning dari pressure gauge ke tap valve refrigerant kaleng, pastikan sudah tersambung rapat

4. Kemudian buka keran refrigerant, pada hose warna kuning kendorkan sedikit dibagian 
sambungan dekat pressure gauge tujuannya agar udara dapat keluar.

5. Letakkan kaleng refrigerant kaleng diatas timbangan, kemudian catat berat awalnya

6. Kemudian sambungkan motor listrik dengan arus 220 V kemudian hidupkan switch motor

7. Hidupkan switch battery, extra fan, dan fan Blower

8. Buka valve pressure gauge pada sisi tekanan rendah lihat jarum penunjuk di sisi tekanan rendah

9. Isikan refrigerant sampai berat awal dari refrigerant berkurang sebesar 100 gram, itu berarti refrigerant yang sudah masuk ke dalam sistem sudah mencapai 100 gram

10. Kemudian tutup semua valve pressure gauge lepas hose warna kuning dari kaleng refrigerant, lepas hose pada sisi tekanan rendah dan tekanan tinggi pada kompresor.

11. Catat hasil dari penelitian dari berat massa refrigerant

12. Kemudian ulangi langkah 8 sampai 11 untuk pengukuran massa refrigerant 200 gram dan massa refrigerant 300 gram

\section{Cara Kerja Sistem Simulator AC Mobil}

Saat motor listrik disambungkan dengan arus listrik $220 \mathrm{~V}$ dan switch motor sudah dihidupkan maka energi listrik akan dikonversikan menjadi energi gerak yakni putaran, putaran yang dihasilkan oleh motor listrik akan diteruskan untuk memutar kompresor AC mobil dengan tipe 10PA15C melalui V-belt, sehingga kompresor AC mobil akan berputar. Putaran kompresor akan memompa zat refrigerant didalam sistem yang tadi sudah diisi dengan refrigerant $\mathrm{R}-134 \mathrm{a}$, refrigerant yang berasal dari kompresor memiliki tekanan dan suhu yang tinggi dan refrigerant berwujud gas, kemudian akan dipompa menuju ke kondensor.

Pada kondensor memiliki struktur seperti radiator yakni bersirip-sirip dan juga terdapat fin untuk jalur sirkulasinya refrigerant, sirip-sirip pada kondensor berfungsi untuk mempercepat proses pembuangan panas, di kondensor terjadi proses kondensasi yaitu refrigerant yang memiliki suhu tinggi didinginkan dengan bantuan udara dari luar sistem yang dihembuskan oleh extra fan sehingga suhu dari refrigerant akan menurun dan wujudnya akan berubah menjadi cair, kemudian refrigerant akan dialirkan ke receiver dryer.

Pada receiver dryer refrigerant akan difilter sehingga jika ada uap air ataupun kotoran berupa debudebu yang mungkin saja ikut terbawa kedalam sistem tidak ikut terbawa ke katup ekspansi yang akan mengakibatkan kebuntuan, di reeceiver dryer juga terdapat sigh glass yang berfungsi untuk mengetahui jumlah refrigerant didalam sistem. Setelah refrigerant melewati receiver dryer kemudian refrigerant akan menuju ke katup ekspansi (Katup ekspansi).

Pada Katup ekspansi memiliki saluran refrigerant yang sangat kecil kemudian akan dlewatkan ke saluran yang lebih besar, sehingga refrigerant yang melewati saluran yang lebih kecil dan kemudian saat mencapai saluran yang lebih besar secara tiba-tiba maka tekanan pada refrigerant akan meningkat saat melewati saluran yang lebih kecil dan akan tiba-tiba menurun saat di saluran yang lebih besar yang akan membuat suhu refrigerant akan menurun dan wujudnya akan berubah menjadi kabut (cair dan gas).

Kemudian suhu refrigerant yang sudah turun akan melewati evaporator, dievaporator strukturnya mirip seperti kondensor meiliki sirip-sirip dan fin, refrigerant yang melewati evaporator akan menyerap panas yang ada disekelilingnya sehingga udara yang ada disekitar evaporator akan menjadi lebih dingin dan suhu refrigerant akan naik (karena menerima suhu panas dari udara disekitar) sehingga wujudnya akan berubah menjadi gas, kemudian refrigerant akan kembali ke kompresor dan sirkulasi refrigerant di dalam sistem terus berulang-ulang selama AC terus hidup.

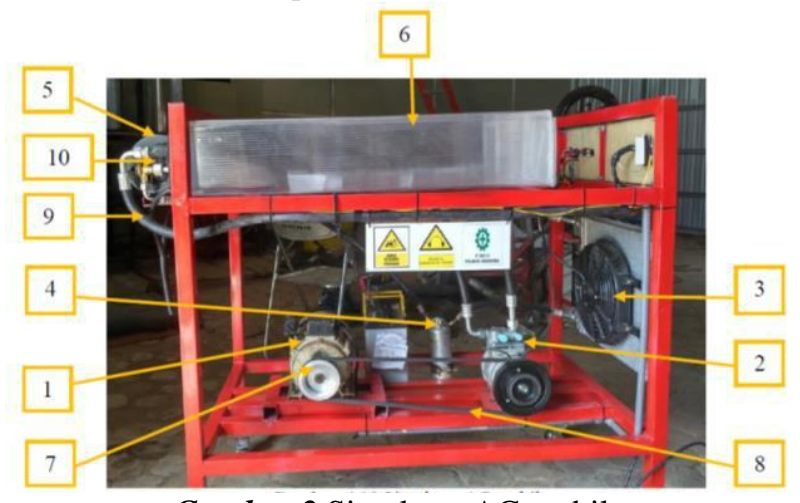

Keterangan :

1. Motor listrik

2. Kompresor

3. Kondensor

4. Receiver dryer

5. Evaporator

6. Ruang kabin

7. Pulley

8. V-Belt

9. Hose

10. Katup Ekspansi

\section{Pengujian Sistem Kerja Simulator AC Mobil Pengujian Massa Refrigerant Terhadap Simulator AC Mobil}

Setelah sistem di vacum kemudian isikan zat refrigerant HFC R-134a kedalam sistem, maka selanjutnya adalah melakukan pengujian atau penelitian pada sistem dengan variasi massa refrigerant terhadap putaran motor listrik, tekanan kerja refrigerant, suhu pada kondensor dan suhu pada rungan kabin, brikut ini adalah tabel hasil pengujian : 
Tabel 1 Pengaruh variasi massa refrigerant terhadap sistem kerja simulator AC mobil

\begin{tabular}{|c|c|c|c|c|c|c|}
\hline \multirow{2}{*}{$\begin{array}{c}\text { Massa } \\
\text { Refrigerant }\end{array}$} & \multicolumn{2}{|c|}{$\begin{array}{c}\text { Tekanan Kerja } \\
\text { Refrigerant }\end{array}$} & \multirow{2}{*}{ Waktu (s) } & \multirow{2}{*}{$\begin{array}{l}\text { Rpm } \\
\text { Motor } \\
\text { Listrik }\end{array}$} & \multirow{2}{*}{$\begin{array}{c}\text { Suhu } \\
\text { Kondensor } \\
\left({ }^{\circ} \mathrm{C}\right)\end{array}$} & \multirow{2}{*}{$\begin{array}{c}\text { Suhu } \\
\text { Kabin } \\
\left({ }^{\circ} \mathrm{C}\right)\end{array}$} \\
\hline & $\begin{array}{l}\text { Tekanan } \\
\text { Rendah }\end{array}$ & $\begin{array}{c}\text { Tekanan } \\
\text { Tinggi }\end{array}$ & & & & \\
\hline \multirow{7}{*}{100 gram } & \multirow{7}{*}{$4 \mathrm{Psi}$} & \multirow{7}{*}{$120 \mathrm{Psi}$} & $0 \mathrm{~s}$ & 1500 & 31,5 & 31,2 \\
\hline & & & $30 \mathrm{~s}$ & \multirow{2}{*}{1446} & 34,7 & 28,9 \\
\hline & & & $60 \mathrm{~s}$ & & 40,9 & 27,8 \\
\hline & & & $90 \mathrm{~s}$ & \multirow{2}{*}{1444} & 43 & 26,8 \\
\hline & & & $120 \mathrm{~s}$ & & 47,7 & 26,6 \\
\hline & & & $150 \mathrm{~s}$ & \multirow{2}{*}{1442} & 50,1 & 26,3 \\
\hline & & & $180 \mathrm{~s}$ & & 53,7 & 26,3 \\
\hline \multirow{7}{*}{200 gram } & \multirow{7}{*}{$12 \mathrm{Psi}$} & \multirow{7}{*}{$150 \mathrm{Psi}$} & $0 \mathrm{~s}$ & 1500 & 31,2 & 31 \\
\hline & & & $30 \mathrm{~s}$ & \multirow{2}{*}{1423} & 35,7 & 29,7 \\
\hline & & & $60 \mathrm{~s}$ & & 43,6 & 25,6 \\
\hline & & & $90 \mathrm{~s}$ & \multirow{2}{*}{1419} & 49 & 23.7 \\
\hline & & & $120 \mathrm{~s}$ & & 51,3 & 22,2 \\
\hline & & & $150 \mathrm{~s}$ & \multirow{2}{*}{1416} & 51,5 & 21,5 \\
\hline & & & $180 \mathrm{~s}$ & & 55,5 & 19,3 \\
\hline \multirow{7}{*}{300 gram } & \multirow{7}{*}{$20 \mathrm{Psi}$} & \multirow{7}{*}{$195 \mathrm{Psi}$} & 0s & 1500 & 31,6 & 31,7 \\
\hline & & & $30 \mathrm{~s}$ & \multirow{2}{*}{1390} & 38,4 & 23,7 \\
\hline & & & $60 \mathrm{~s}$ & & 46 & 16,8 \\
\hline & & & $90 \mathrm{~s}$ & \multirow{2}{*}{1380} & 50,7 & 14,6 \\
\hline & & & $120 \mathrm{~s}$ & & 53,7 & 12,4 \\
\hline & & & $150 \mathrm{~s}$ & \multirow{2}{*}{1372} & 55,8 & 11,8 \\
\hline & & & $180 \mathrm{~s}$ & & 58,8 & 11,4 \\
\hline
\end{tabular}

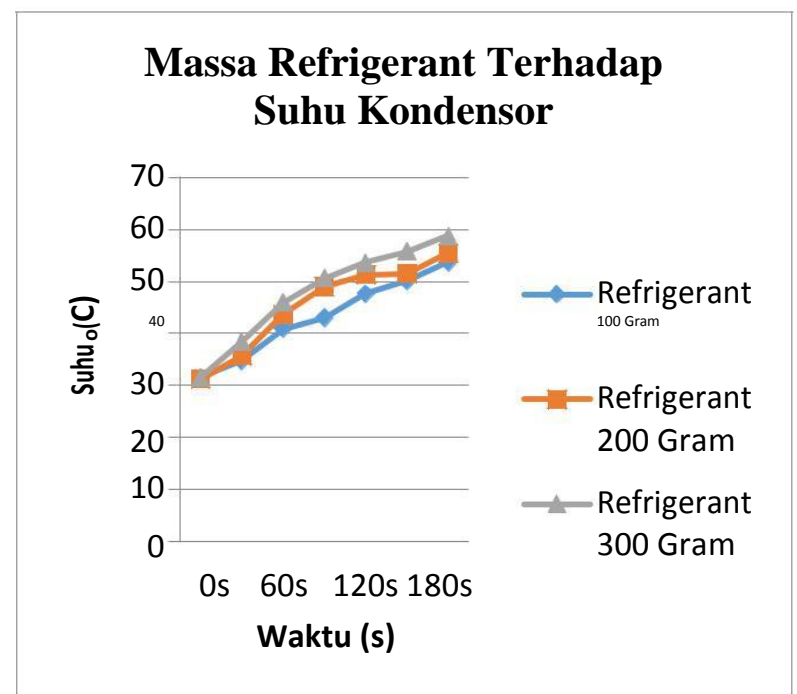

Gambar 3 Grafik massa refrigerant terhadap suhu kondensor

\section{Massa Refrigerant Terhadap Suhu Evaporator (Ruang Kabin)}

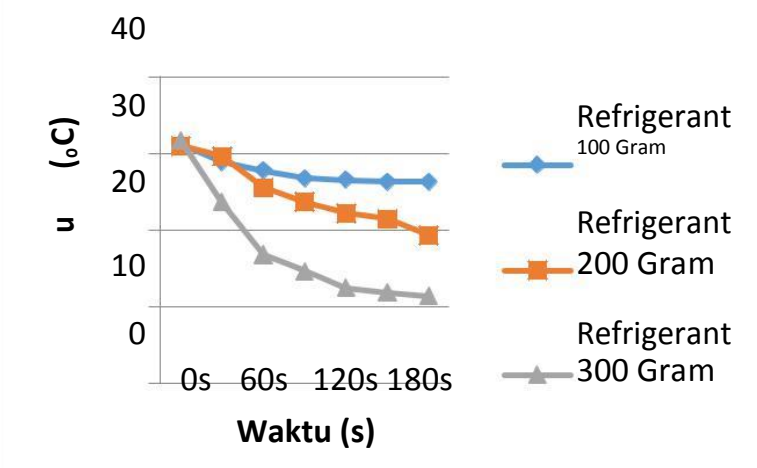

Gambar 4 Grafik massa refrigerant terhadap suhu evaporator
Berdasarkan data hasil pengujian diatas dengan semakin berat massa refrigerant yang ada didalam sistem, maka refrigerant yang bisa di kompresikan oleh kompresor akan semakin banyak, sehingga tekanan kerja refrigerant yang ada di sisi tekanan rendah dan di sisi tekanan tinggi akan mengalami kenaikan terlihat pada pengujian refrigerant 100 gram tekanan kerja refrigerantnya pada tekanan rendah adalah 4 Psi dan pada tekanan tinggi adalah 120 Psi, pada pengujian refrigerant 200 gram tekanan kerja refrigerantnya pada tekanan rendah adalah 12 Psi dan pada tekanan tinggi adalah 150 Psi, pada pengujian refrigerant 300 gram tekanan kerja refrigerantnya pada tekanan rendah adalah 20 Psi dan pada tekanan tinggi adalah 195 Psi, ini membuat kinerja dari motor listrik akan semakin berat sehingga putaran rpm nya akan menurun seiring dengan massa refrigerant yang bertambah terlihat pada pengujian refrigerant 100 gram rpm motor listriknya adalah 1436, pada pengujian refrigerant 200 gram rpm motor listriknya adalah 1420, pada pengujian refrigerant 300 gram rpm motor listriknya adalah 1357.

Karena massa refrigerant didalam sistem bertambah itu artinya semakin banyak jumlah refrigerant yang dapat di sirkulasikan oleh kompresor didalam sistem, sehingga proses penyerapan panas diarea sekitar evaporator pun akan lebih baik dan suhu yang dihasilkan akan lebih cepat turun terlihat pada pengujian refrigerant $100 \mathrm{gm}$ suhu yang dapat dihasilkan oleh evaporator selama 3 menit adalah $26,3^{\circ} \mathrm{C}$, pada pengujian refrigerant $200 \mathrm{gm}$ suhu yang dapat dihasilkan oleh evaporator selama 3 menit adalah $19,3^{\circ} \mathrm{C}$, pada pengujian refrigerant 300 gm suhu yang dapat dihasilkan oleh evaporator selama 3 menit adalah $11,4^{\circ} \mathrm{C}$. Itu berarti panas yang dapat dibuang pada kondensor akan semakin banyak, ini yang menyebabkan pembuangan panas pada kondensor akan semakin cepat seiring dengan naiknya massa refrigerant yang ada di dalam sistem itu terlihat pada refrigerant 100 gram suhu yang ada pada kondensor dalam waktu 3 menit mencapai $53,7^{\circ} \mathrm{C}$, pada refrigerant 200 gram suhu yang ada pada kondensor dalam waktu 3 menit mencapai $55,5^{\circ} \mathrm{C}$, pada refrigerant 300 gram suhu yang ada pada kondensor dalam waktu 3 menit mencapai $58,8^{\circ} \mathrm{C}$, hal ini juga membuktikan bahwa dengan semakin banyaknya massa refrigerant didalam sistem maka laju aliran massa refrigerant juga akan bertambah semakin cepat. 
Pengujian Pengaruh Massa Refrigerant dan Kecepatan Blower Evaporator Terhadap Simulator AC Mobil

Tabel 2 pengaruh variasi massa refrigerant terhadap rpm motor listrik

\begin{tabular}{|c|c|c|c|}
\hline $\begin{array}{c}\text { Massa } \\
\text { Refrigerant }\end{array}$ & $\begin{array}{c}\text { Kecepatan } \\
\text { Blower }\end{array}$ & Waktu & $\begin{array}{c}\text { Rpm } \\
\text { Motor } \\
\text { Listrik }\end{array}$ \\
\hline \multirow{6}{*}{100 gram } & \multirow{3}{*}{ Kecepatan 1} & 1 menit & 1446 \\
\hline & & 2 menit & 1444 \\
\hline & & 3 menit & 1442 \\
\hline & \multirow{3}{*}{ Kecepatan 3} & 1 menit & 1441 \\
\hline & & 2 menit & 1438 \\
\hline & & 3 menit & 1435 \\
\hline \multirow{6}{*}{200 gram } & \multirow{3}{*}{ Kecepatan 1} & 1 menit & 1423 \\
\hline & & 2 menit & 1421 \\
\hline & & 3 menit & 1419 \\
\hline & \multirow{3}{*}{ Kecepatan 3} & 1 menit & 1420 \\
\hline & & 2 menit & 1411 \\
\hline & & 3 menit & 1408 \\
\hline \multirow{6}{*}{300 gram } & \multirow{3}{*}{ Kecepatan 1} & 1 menit & 1390 \\
\hline & & 2 menit & 1380 \\
\hline & & 3 menit & 1372 \\
\hline & \multirow{3}{*}{ Kecepatan 3} & 1 menit & 1384 \\
\hline & & 2 menit & 1375 \\
\hline & & 3 menit & 1365 \\
\hline
\end{tabular}

Tebel 3 Pengaruh Massa refrigerant dan kecepatan blower terhadap tekanan kerja refriegrant

\begin{tabular}{|c|c|c|c|}
\hline \multirow{2}{*}{$\begin{array}{c}\text { Massa } \\
\text { Refrigerant }\end{array}$} & \multirow{2}{*}{$\begin{array}{c}\text { Kecepatan } \\
\text { Blower }\end{array}$} & \multicolumn{2}{|c|}{$\begin{array}{c}\text { Tekanan Kerja } \\
\text { Refrigerant }\end{array}$} \\
\hline & & $\begin{array}{l}\text { Tekanan } \\
\text { Rendah }\end{array}$ & $\begin{array}{c}\text { Tekanan } \\
\text { Tinggi }\end{array}$ \\
\hline \multirow{2}{*}{$\begin{array}{l}\text { Refrigerant } \\
100 \text { gram }\end{array}$} & $\begin{array}{c}\text { Kecepatan } \\
1\end{array}$ & 4 Psi & 120 Psi \\
\hline & $\begin{array}{l}\text { Kecepatan } \\
3\end{array}$ & 4 Psi & 120 Psi \\
\hline \multirow{2}{*}{$\begin{array}{l}\text { Refrigerant } \\
200 \text { gram }\end{array}$} & $\begin{array}{c}\text { Kecepatan } \\
1\end{array}$ & 12 Psi & 150 Psi \\
\hline & $\begin{array}{l}\text { Kecepatan } \\
3\end{array}$ & 12 Psi & 150 Psi \\
\hline \multirow{2}{*}{$\begin{array}{l}\text { Refrigerant } \\
300 \text { gram }\end{array}$} & $\begin{array}{c}\text { Kecepatan } \\
1\end{array}$ & 20 Psi & 195 Psi \\
\hline & $\begin{array}{l}\text { Kecepatan } \\
3\end{array}$ & 20 Psi & 195 Psi \\
\hline
\end{tabular}

\section{Massa refrigerant 100 gram dan Kecepatan Blower terhadap Suhu Kondensor}

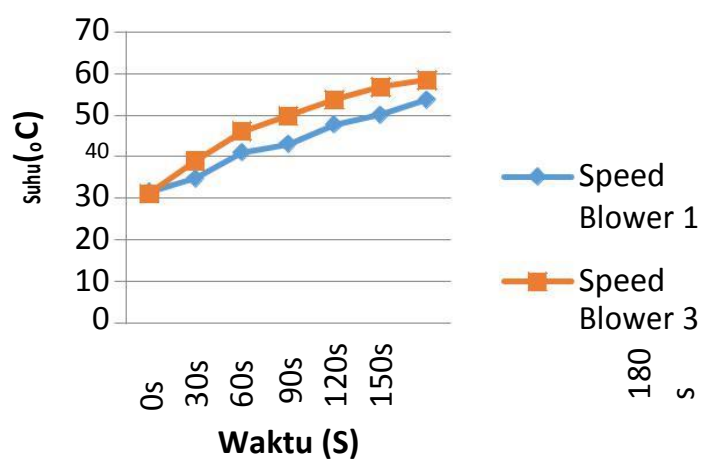

Gambar 5 Grafik massa refrigerant 100 gram terhadap suhu kondensor

\section{Massa refrigerant 200 gram dan Kecepatan Blower terhadap Suhu Kondensor}

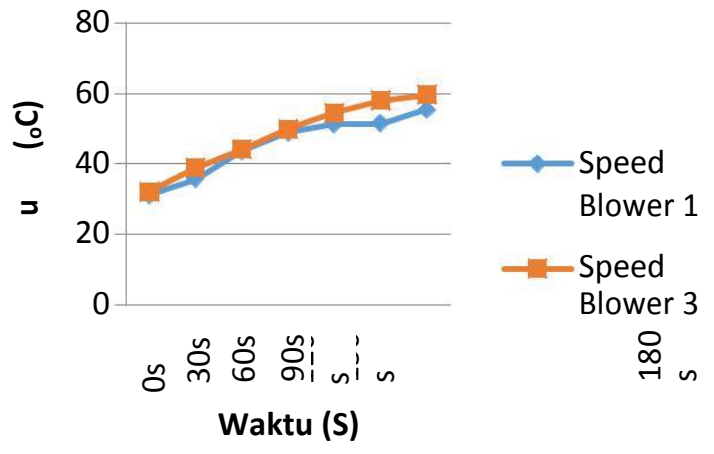

Gambar 6 Grafik massa refrigerant 200 gram terhadap suhu kondensor

\section{Massa refrigerant 300 gram dan Kecepatan Blower terhadap Suhu Kondensor}

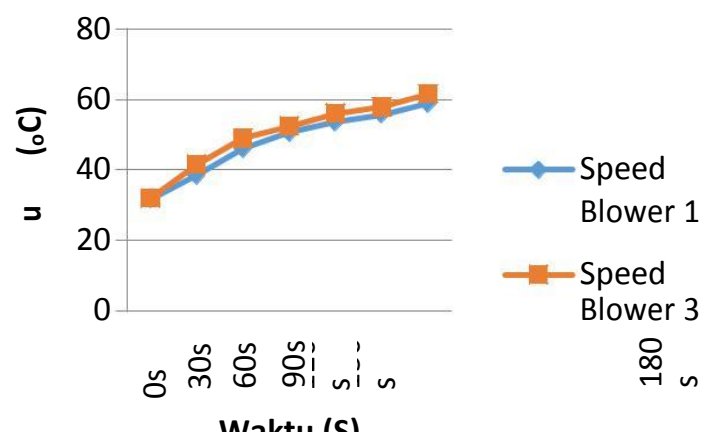

Gambar 7 Grafik massa refrigerant 300 gram terhadap suhu kondensor 


\section{Massa refrigerant 100 gram dan Kecepatan Blower terhadap Suhu Evaporator}

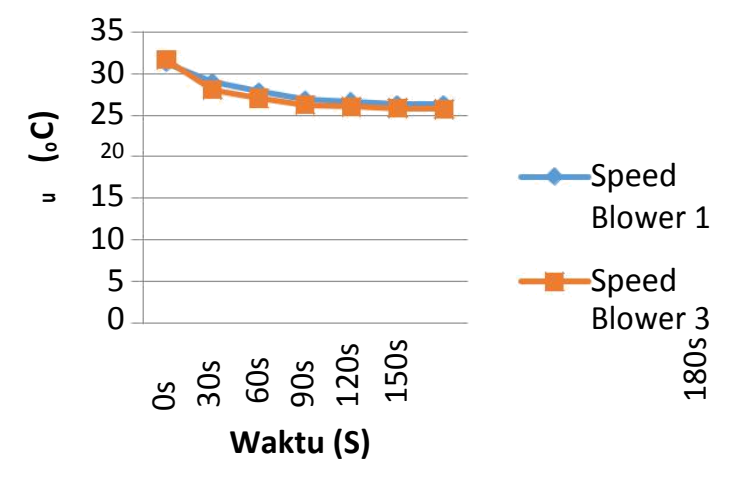

Gambar 8 Grafik massa refrigerant 100 gram terhadap suhu Evaporator

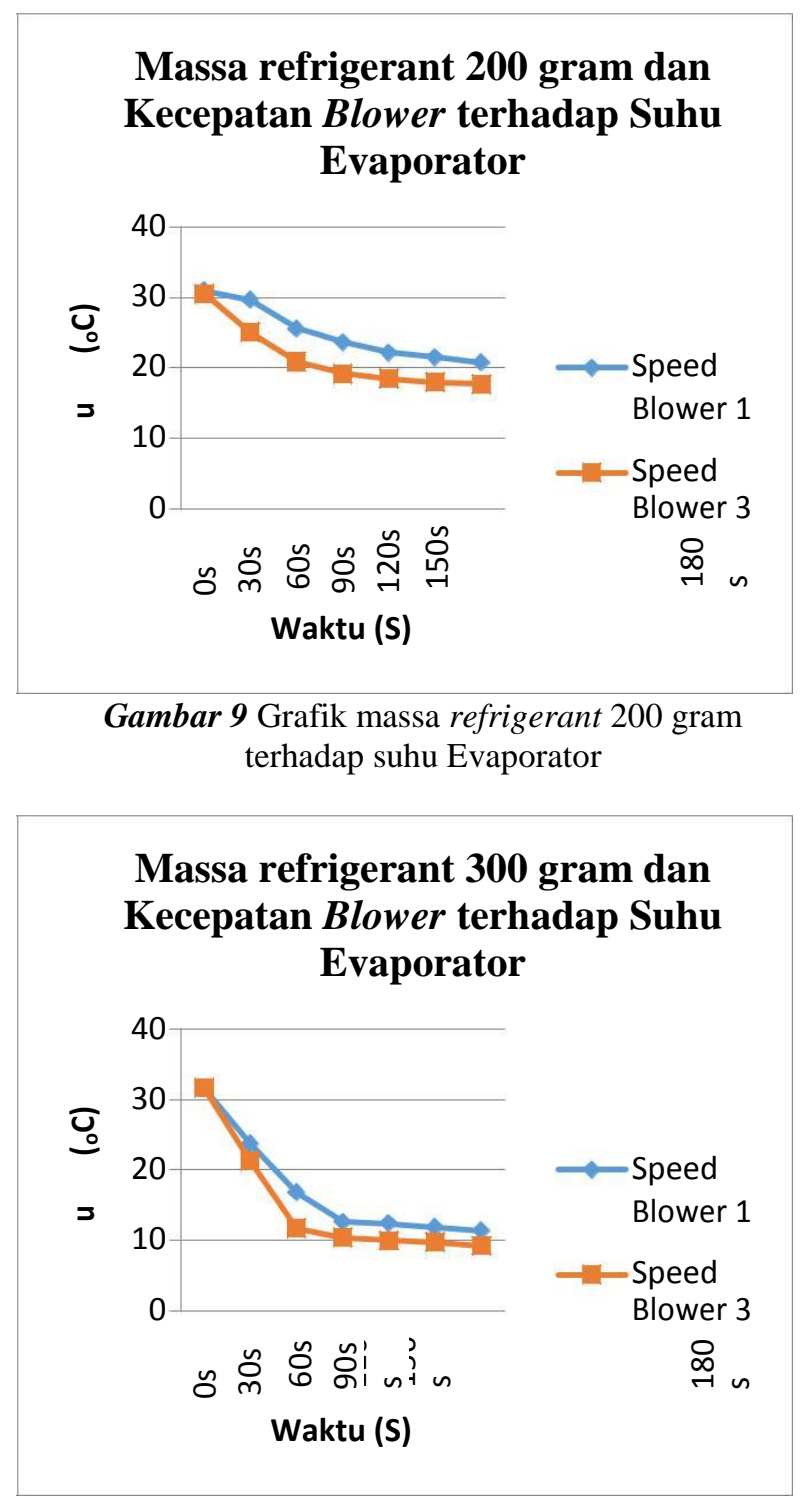

Gambar 10 Grafik massa refrigerant 300 gram terhadap suhu Evaporator
Berdasarkan data dari hasil penelitian diatas tentang pengaruh massa refrigerant dan kecepatan blower terhadap simulator AC mobil (rpm motor listrik, tekanan kerja refrigerant, suhu kondensor dan suhu evaporator) maka dapat disimpulkan bahwa semakin berat massa refrigerant yang ada di dalam sistem dan semakin cepat kecepatan blower evaporator akan membuat putaran rpm motor listrik menurun hal ini diakiatkan karena semakin berat massa refrigerant didalam sistem akan membuat tekanan kerja refrigerant didalam sistem akan meningkat, dan juga dengan semakin cepatnya proses pendinginan yang terjadi di evaporator maka akan membuat sedikit perbedaan hal ini dapat terlihat pada massa refrigerant 100 gram dan pada kecepatan blower 1, rpm motor listriknya adalah 1446 pada menit awal percobaan dan menjadi 1442 pada akhir percobaan, sedangkan pada kecepatan blower 3, rpm motor listriknya adalah 1441 pada awal percobaan dan menjadi 1435 pada akhir percobaan. Pada massa refrigerant 200 gram dan pada kecepatan blower 1, rpm motor listriknya adalah 1423 pada menit awal percobaan dan menjadi 1416 pada akhir percobaan, sedangkan pada kecepatan blower 3, rpm motor listriknya adalah 1423 pada awal percobaan dan menjadi 1408 pada akhir percobaan. Pada massa refrigerant 300 gram dan pada kecepatan blower 1, rpm motor listriknya adalah 1390 pada menit awal percobaan dan menjadi 1372 pada akhir percobaan, sedangkan pada kecepatan blower 3, rpm motor listriknya adalah 1384 pada awal percobaan dan menjadi 1365 pada akhir percobaan.

Pada tekanan kerja refrigerant pada pressure gauge pada setiap percobaan terlihat tidak ada mengalami perbedaan untuk penelitian berdasarkan kecepatan blower 1 maupun kecepatan blower 3, namun untuk percobaan berdasarkan massa refrigerant terlihat perbedaan yang sangat jauh yaitu pada massa refrigerant 100 gram dengan kecepatan blower 1 dan kecepatan blower 3 pada sisi tekan rendah adalah 4 Psi dan pada sisi tekanan tingginya adalah 120 Psi. Pada massa refrigerant 200 gram dengan kecepatan blower 1 dan kecepatan blower 3 pada sisi tekan rendah adalah 12 Psi dan pada sisi tekanan tingginya adalah 150 Psi. Pada massa refrigerant 300 gram dengan kecepatan blower 1 dan kecepatan blower 3 pada sisi tekan rendah adalah 20 Psi dan pada sisi tekanan tingginya adalah 195 Psi. Pada hasil penelitian ini terlihat bahwa tidak ada perubahan pada kecepatan blower 1 maupun kecepatan blower 3 pada tekanan kerja refrigerant yang terlihat pada pressure gauge, padahal pada pengujian rpm motor listrik pada kecepatan blower 1 dan kecepatan blower 3 terlihat ada sedikit perbedaan, hal ini dapat terjadi karena pada setiap alat ukur itu memiliki tingkat ketelitian yang berbeda-beda, dari sini terlihat bahwa preesure gauge memiliki ketelitian yang kurang baik. 
Pada pelitian massa refrigerant dan kecepatan blower terhadap suhu kondensor dan suhu evaporator, dengan bertambahnya massa refrigerant yang ada didalam sistem pendingin maka suhu yang dapat diserap diarea sekitar kabin akan semakin banyak, yang artinya panas yang dapat dibuang pada kondensor juga akan semakin banyak. Perbedaan kecepatan blower evaporator juga sedikit memberikan perbedaan terhadap suhu yang dapat diserap diarea evaporator, sehingga pastinya akan terjadi perbedaan terhadap suhu pada kondensor, hal ini dapat dilihat dari hasil data hasil penitian. Pada massa refrigerant 100 gram dan dengan kecepatan blower 1 suhu yang dapat dihasilkan pada evaporator atau ruang kabin adalah $26,3^{\circ} \mathrm{C}$, sedangkan pada kecepatan blower 3 suhu yang dapat dihasilkan adalah $25,7^{\circ} \mathrm{C}$. Pada massa refrigerant 200 gram dan dengan kecepatan blower 1 suhu yang dapat dihasilkan pada evaporator atau ruang kabin adalah $20,8^{\circ} \mathrm{C}$, sedangkan pada kecepatan blower 3 suhu yang dapat dihasilkan adalah $17,7^{\circ} \mathrm{C}$. Pada massa refrigerant 100 gram dan dengan kecepatan blower 1 suhu yan dapat dihasilkan pada evaporator atau ruang kabin adalah $11,4^{\circ} \mathrm{C}$, sedangkan pada kecepatan blower 3 suhu yang dapat dihasilkan adalah $9,2^{\circ} \mathrm{C}$. Karena suhu yang dapat dihasilkan pada evaporator itu berarti suhu yanng dapat dibuang pada kondensor akan meningkan, ini dapat dilihat dari hasil data penelitian sebagai berkut pada kondensor suhu yang ada pada kondensor dalam waktu 3 menit adalah, pada refrigerant 100 gram dan dengan kecepatan blower 1 suhu yang ada pada kondensor mencapai $53,7^{\circ} \mathrm{C}$, sedangan dengan kecepatan blower 3 suhu yang ada pada kondensor mencapai $53,8^{\circ} \mathrm{C}$. Pada refrigerant 200 gram dan dengan kecepatan blower 1 suhu yang ada pada kondensor mencapai $55,7^{\circ} \mathrm{C}$, sedangan dengan kecepatan blower 3 suhu yang ada pada kondensor mencapai $59,8^{\circ} \mathrm{C}$. pada refrigerant 300 gram dan dengan kecepatan blower 1 suhu yang ada pada kondensor mencapai $58,8^{\circ} \mathrm{C}$, sedangan dengan kecepatan blower 3 suhu yang ada pada kondensor mencapai $61,6^{\circ} \mathrm{C}$.

\section{KESIMPULAN}

1. Proses pengisian refrigerant berdasarkan berat massanya yakni dengan cara mencatat berat awal dari refrigrant yang akan digunakan kemudian buka valve pressure gauge dan perhatikan perubahan berat pada refrigerant yang digunakan. Kemudian cara kerja dari simulator ini adalah dengan mengubah energi listrik menjadi energi mekanik menggunakan motor listrik yang kemudian tenaganya akan dihubungkan dengan kompresor, sehingga kompresor dapat berputar dan membuat terjadinya sirkulasi refrigerant di dalam sistem.

2. Massa refrigerant sangat berpengaruh terhadap sistem kerja simulator AC mobil, Rpm motor listrik paling tinggi adalah pada massa refrigerant 100 gram yaitu 1446. Tekanan kerja refrigerant paling tinggi adalah pada massa refrigerant 300 gram yaitu 20 Psi / 195 Psi. Suhu kondensor paling tingi adalah pada massa refrigerant 300 gram yaitu mencapai $58,8^{\circ} \mathrm{C}$. Dan suhu evaporator paling dingin adalah pada massa refrigerant 300 gram yaitu mencapai $11,4^{\circ} \mathrm{C}$

3. Kecepatan blower evaporator juga berpengaruh terhadap sistem kerja dari simulatir AC mobil, namun tidak terlalu signifikan. Di setiap massa refrigerant $\mathrm{rpm}$ motor listrik paling tinggi adalah saat massa refrigerant 100 gram dan dengan kecepatan blower 1 yaitu 1446. Suhu kondensor paling tingi adalah pada massa refrigerant 300 gram dan dengan kecepatan blower 3 yaitu mencapai $61,6^{\circ} \mathrm{C}$. Dan suhu evaporator paling dingin adalah pada massa refrigerant 300 dan dengan kecepatan blower 3 gram yaitu mencapai $9,2^{\circ} \mathrm{C}$

\section{DAFTAR PUSTAKA}

[1] BPS. (2017). perkembangan jumlah kendaran bermotor menurut jenisnya. Dipetik januari 20, 2018,dariwww.bps.go.id: www.BPS.go.id/Tabeldinamis/view/id/1133

[2] Sinaga, N. d. (2013). Rancang bangun sistem panyalaan AC mobil dari jarak jauh menggunakan mikrokontroler. Jurnal Teknik Mesin , 202. 